\title{
Digital removable partial dentures
}

\author{
Faleh Tamimi $^{1}$ (D ) Balqees Almufleh ${ }^{2,3} \cdot$ Eric Caron $^{4} \cdot$ Omar Alageel $^{2,5}$
}

Received: 4 April 2020 / Accepted: 17 April 2020 / Published online: 4 May 2020

(c) The Author(s) 2020

\begin{abstract}
Recently, digital techniques have revolutionized the production of partial removable dental prostheses (PRDPs). This chapter reviews current systems for PRDP production, how they are done in clinical practice, advantages and limitations, and current literature regarding their clinical performance. Currently, several digital techniques are available in the market for PRDP production including subtractive and additive techniques. Subtractive milling technique is mainly effective for non-metal PRDP, whereas additive techniques are used mainly in metal PRDP. Digital techniques expand the range of materials that can be utilized for PRDP production, including new polymers (PEEK), and facilitate previously difficult procedures such as casting titanium PRDP, which can be produced more easily with digital methods. This review shows that available evidence suggests that these techniques have promising clinical results. Laser sintering resulted in higher patient's satisfaction compared to conventional PRDP. However, long-term clinical trials are recommended to explore the long-term effects of these techniques. Moreover, this review showed the lack of evidence on the clinical performance of non-metal partial removable dental prostheses.
\end{abstract}

Keywords Partial removable dental prosthesis - Laser sintering $\cdot 3 \mathrm{D}$ printing $\cdot$ Nonmetal PRDP $\cdot$ CAD-CAM $\cdot$ Stereolithography $\cdot$ Casting

\section{Quick reference/description}

Partial removable dental prostheses (PRDPs) are a non-invasive treatment alternative for partially edentulous patients. The production of PRDP has been revolutionized by the introduction of digital techniques for the fabrication of metal and nonmetal PRDP. Several digital techniques of PRDP production are currently available that save time, increase productivity, and decrease human error.

Faleh Tamimi

faleh.tamimimarino@mcgill.ca; fmarino@qu.edu.qa

Extended author information available on the last page of the article 


\section{Indications}

Treatment of partially edentulous patients.

\section{Materials/instruments}

- Alginate impression material

- 3D scanners (intraoral and extraoral)

- Rubber-based impression materials

- Designing equipment (with or without physical sculptor)

- Laser-sintering equipment

- 3D printing equipment

- Milling equipment

- Polyether ether ketone

- Ultaire aryl ketone polymer

- Acetyl copolymer

- Polyethylene terephthalate

- Polymethylmethacrylate

- Polyamide

- Finishing burs

- Barrels of ceramic and corn

- Electropolishing device

\section{Procedure}

Partial removable dental prostheses (PRDPs) are a prevalent and economic treatment modality to enhance the quality of life of partially edentulous patients. Initially, PRDPs were produced from and cast metal alloys using the lost-wax technique. Eventually, computer-aided design and digital milling manufacturing techniques were developed. However, as milling manufacturing of metal PRDP is difficult, stereolithography printing of wax or resin sacrificial patterns for casting PRDP metal frameworks was introduced. Laser-sintering technique was also developed for digital production of PRDP frameworks to eliminate the need for metal investing and casting. More recently, milling methods have regained interest with the development of new polymeric materials for PRDP frameworks. Currently, PRDPs produced with digital methods are made of metal alloys or non-metal materials like nylon-based polyamide (Valplast), polyether ether ketone, etc. (Table 1).

The digital design of the frameworks was initially performed with a physical sculptor, a haptic device for manipulating objects in a three-dimensional virtual environment. Specialized software was then introduced to overcome the limitations of PRDP production and avoid the need for a physical sculptor. Also, laser 


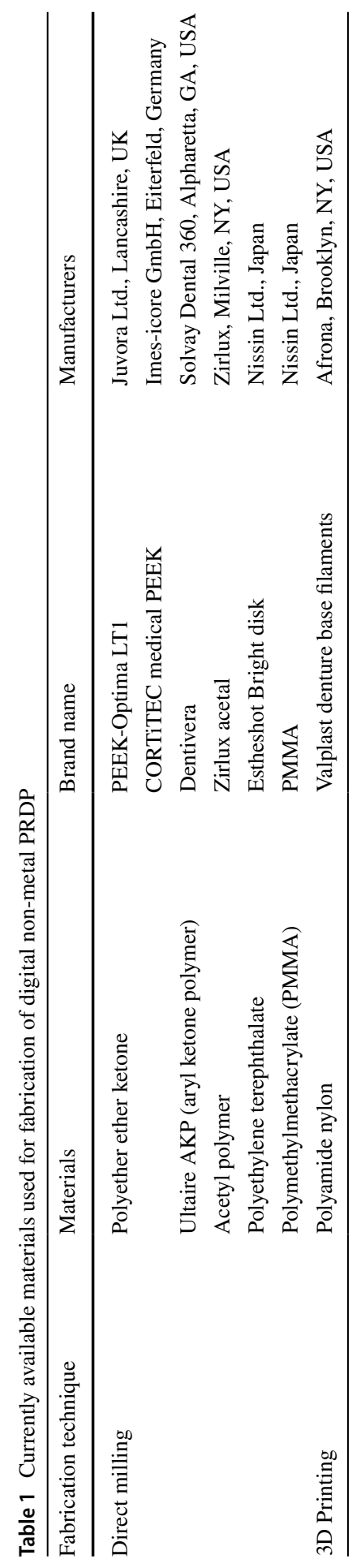


sintering with high-speed high-precision milling was developed for PRDP fabrication with smoother surfaces and higher precision. This is particularly useful for the production of titanium PRDPs.

Digital production of PRDPs has become prevalent and is gaining popularity due to its various advantages such as improved quality and faster manufacturing. The current methods of PRDP production include case digitization with intraoral or extraoral laboratory 3D scanners followed by designing of the PRDP frameworks using specialized software with or without a physical sculptor. The commercially available digital production systems (Table 2) for metal PRDP are direct metal production systems like laser-sintering systems or indirect metal production systems like stereolithography systems (digital light processing and milling). For digital production of metal-free PRDPs, direct milling of the polymeric materials is the most prevalent technique, and novel 3D filament printing systems are also becoming available.

The procedure for a digital PRDP is initiated after meticulous examination and treatment planning. It is performed as follows:

\section{Acquisition}

- Alginate impression material is used to make primary impressions that are then poured into diagnostic casts.

- Careful case evaluation is performed from the diagnostic cast, and a design for the PRDP is planned. Simultaneously, planning of abutment teeth preparations is also done. The abutment teeth are prepared as per the PRDP design.

- After tooth preparation, intraoral or extraoral scanning of the patient's arches is performed. Intraoral scanning is performed with an intraoral scanner, thereby, eliminating the requirement of a physical impression. This includes several scans of both arches requiring about 3-17 min. The scans are then joined by the software resulting in a full-mouth image. Intraoral scanning is particularly effective in Kennedy class III cases; however, it does not capture the physiologic extension of the mucosa in Kennedy class I and II cases.

- Alternatively, rubber-based impression materials are used to make final impressions, which are then scanned directly with an extraoral digital scanner or made into master casts and then scanned. In general, bench top scanning of the cast models achieves comparable accuracy regardless of the type of dental stone used.

- Extraoral scanning of either the impressions or the stone-model scans can both provide adequate precision, although, digitalized alginate impressions present considerably better dimensional accuracy than stone models, and the precision of scanned impressions can be further improved using scannable elastomeric impressions materials.

- The scanner generates a stereolithographic file (STL) of the master cast that is imported into the designing software (Fig. 1). 
Table 2 Currently available systems used to fabricate digital metal partial removable dental prostheses

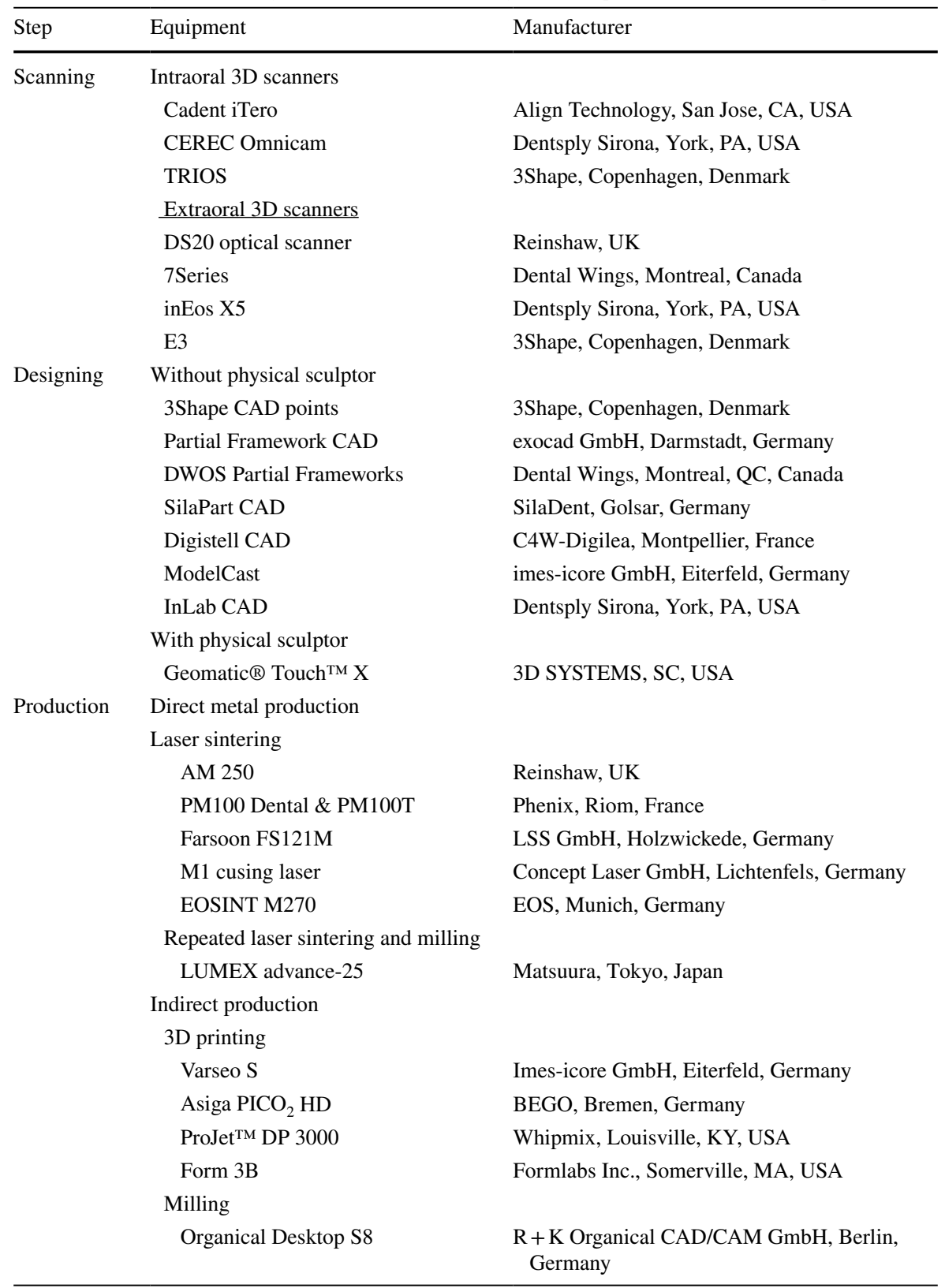

\section{Manipulation}

PRDPs are digitally designed using specialized software through a series of digital steps that simulate traditional laboratory procedures. 

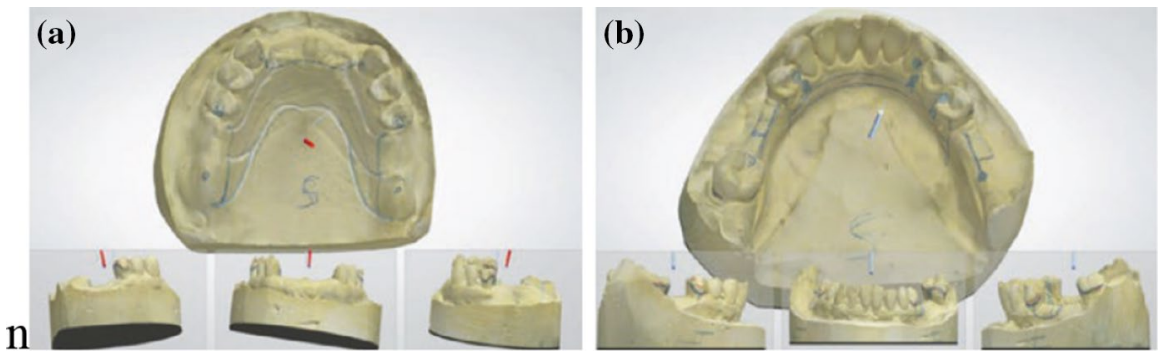

Fig. 1 Virtual casts (STL files) scanned by an extraoral 3D scanner. a Maxillary arch (b) mandibular arch

- Initially, a digital survey tool is used to automatically determine the path of insertion (Fig. 2). The software measures the depth of undercuts and the parallelism and rotates the cast three dimensionally to achieve the best tilt for the path of insertion. Based on these calculations, a survey line is automatically created. This digital step saves time in comparison to the conventional manual procedure.

- After establishing the survey line, the undesirable undercuts are blocked digitally and the sites for the placement of the retentive clasp tips are determined (Fig. 3).

- Thin layers of virtual wax are placed on relief areas, like the rugae.

- After covering the relief areas, meshwork patterns are created and added along with the drawing of major connectors and rests (Figs. 4, 5). The clasp systems and clasp arms are drawn three dimensionally (Fig. 6), and the framework thickness is adjusted and smoothened (Fig. 7).
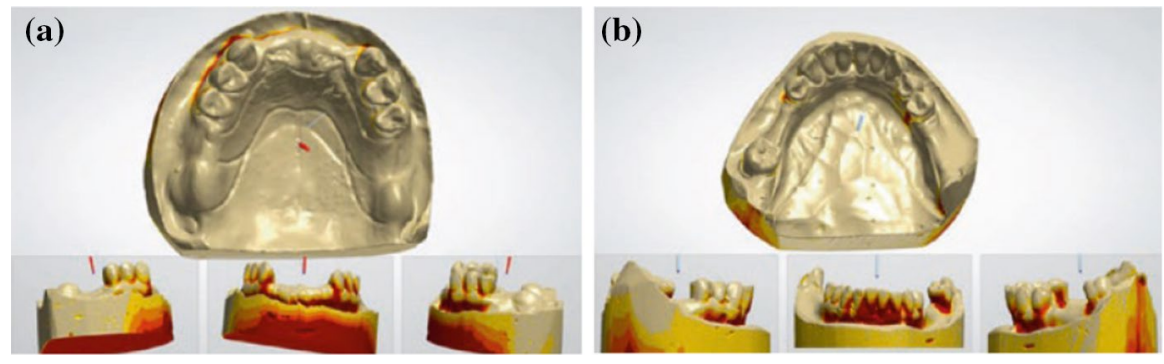

Fig. 2 Virtual determination of the path of insertion of a PRDP using 3Shape CAD points software. a Maxillary arch (b) mandibular arch
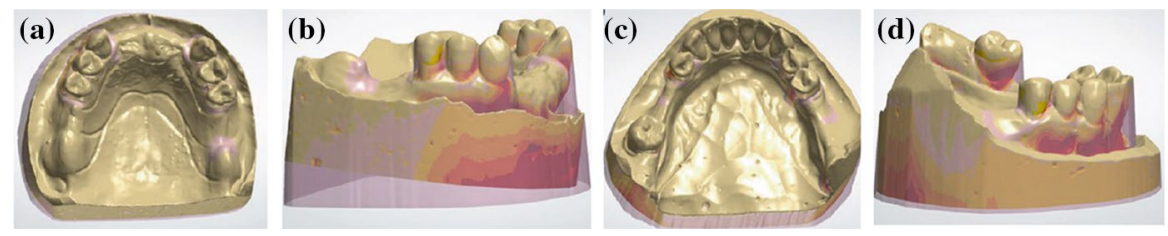

Fig. 3 Virtual blockout of undesirable undercuts using 3Shape CAD points software. a, b Maxillary arch $(\mathbf{c}, \mathbf{d})$ mandibular arch 

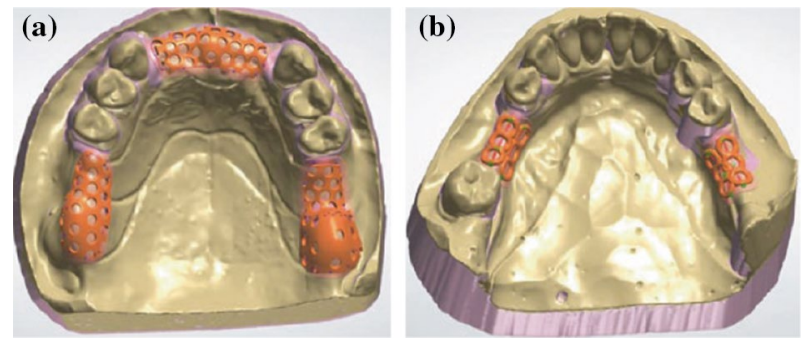

Fig. 4 Virtual building of the meshwork on the edentulous area using the 3Shape CAD points software. a Maxillary arch (b) mandibular arch
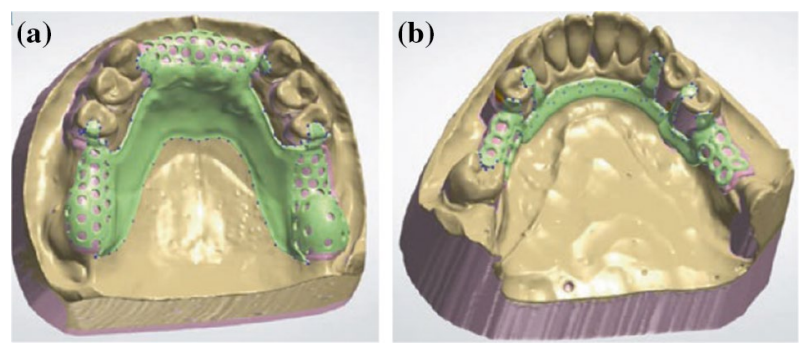

Fig. 5 Virtual building of the major connectors and rests using 3Shape CAD points software. a Maxillary arch (b) mandibular arch
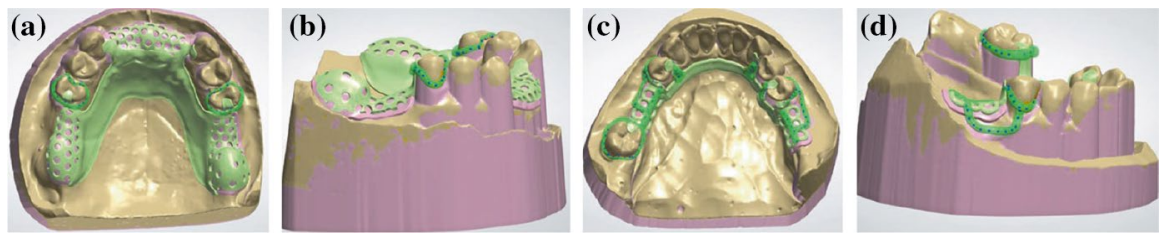

Fig. 6 Virtual building of the clasp arms using 3Shape CAD points software. a, b Maxillary arch (c, d) mandibular arch
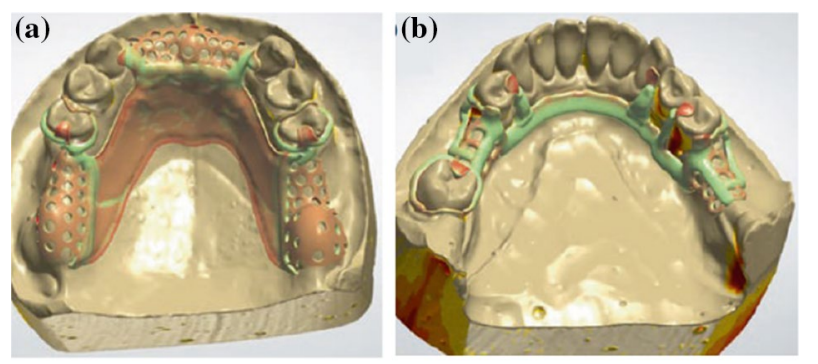

Fig. 7 Virtual adjusting of the thickness of the framework using 3Shape CAD points software. a Maxillary $\operatorname{arch}(\mathbf{b})$ mandibular arch 
- After complete adjustment of the framework, connectors, clasps rests, and finish lines are drawn with the default or customized profiles of the curve tool (Fig. 8). The final designed framework is then finished (Fig. 9).

- A sprue is designed for the casting process in indirect fabrication systems (3D printing and milling).

- Prior to submission of the completed design for additive technology systems (laser-sintering and 3D printing), special supports are added to the structure to hold the prosthesis (Fig. 10). The supports should have enough strength to stabilize the PRDP framework layers during production. During manufacturing, the supports prevent movement and dissipate heat away from the completed part of the framework.

- The entire designing process requires about 30 min for each framework.
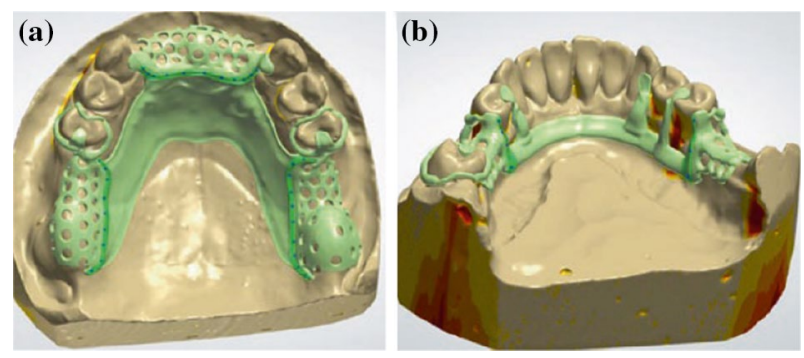

Fig. 8 Virtual drawing of the finish line using 3Shape CAD points software. a Maxillary arch (b) mandibular arch
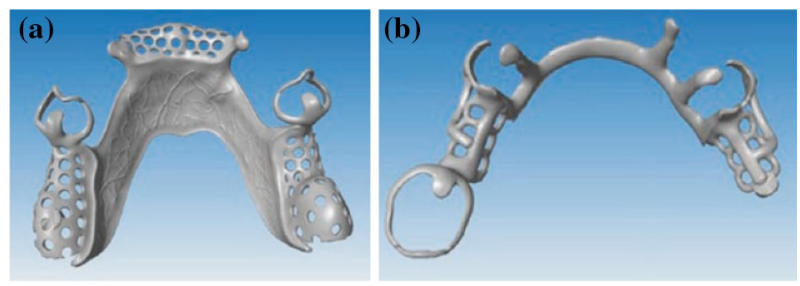

Fig. 9 Finalized virtual design using 3Shape CAD points software. a Maxillary arch (b) mandibular arch
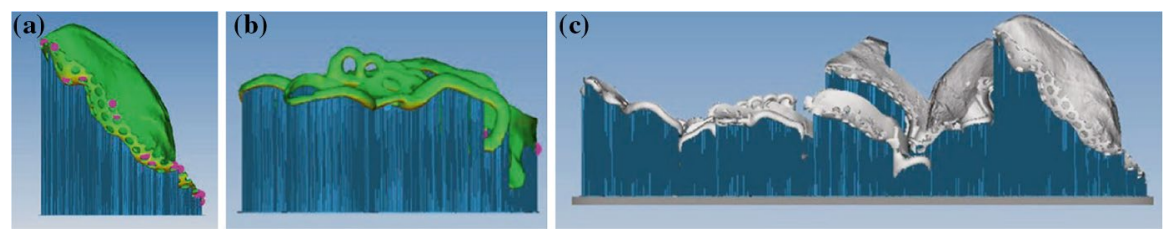

Fig. 10 Illustration of the supports required for successful laser sintering of PRDP. a Maxillary arch (b) mandibular arch (c) PRDP frameworks in the building platform 


\section{Fabrication}

Following completion of the PRDP design, the design file is forwarded to the production machine. The frameworks are developed using direct or indirect production systems (Table 3).

\section{Post-fabrication processing}

- Finishing and polishing of the framework is performed in a series of steps. It is first finished using finishing burs followed by finishing under rotating barrels of ceramics and corns in sequence. Electropolishing is performed for final finishing of the frameworks (Fig. 11).

- The PRDP framework is evaluated for its fit and occlusion in the patient's oral cavity. At this stage, several factors like maxillomandibular relationship and tooth shade and form are selected as for conventional PRDP.

- The framework is forwarded to the laboratory for manual teeth setting, final waxup and acrylization.

- The final PRDP is checked in the patient's mouth for fit, retention and occlusion. It is adjusted if necessary. Following adjustment, the PRDP is finished, polished, and delivered to the patient (Fig. 13).

\section{Advantages of digital PRDPs}

- Digital designing methods save time, as manual surveying and framework waxup is not required.

Table 3 Direct and indirect metal production of PRDP frameworks

\begin{tabular}{lc}
\hline Direct metal production & Indirect metal production \\
\hline $\begin{array}{l}\text { Laser sintering and laser melting are used for direct } \\
\text { metal production of PRDP }\end{array}$ & $\begin{array}{c}\text { Stereolithography, and direct light processing and } \\
\text { milling are used for indirect metal production } \\
\text { of PRDP }\end{array}$ \\
$\begin{array}{l}\text { In these systems, the metal powder is laser sintered } \\
\text { to create the framework (Fig. 11a) }\end{array}$ & $\begin{array}{c}\text { A wax or resin framework pattern is printed or } \\
\text { milled in these systems (Fig. 11b, c, d) }\end{array}$ \\
$\begin{array}{c}\text { A laser-sintering machine requires up to 12 h to } \\
\text { fabricate 12 PRDPs in a single cycle }\end{array}$ & $\begin{array}{c}\text { Following 3D-printing of a framework, multiple } \\
\text { post-curing steps, like removing of wet resin } \\
\text { residue through solvent immersion of the pat- } \\
\text { the printed PRDP is retrieved and sent for post- } \\
\text { fabrication processing }\end{array}$ \\
$\begin{array}{c}\text { For retrieval of the PRDP, it is subjected to heat } \\
\text { treatment according to the manufacturer's instruc- } \\
\text { tions and detached from the supporting base }\end{array}$ & $\begin{array}{l}\text { hardening and achieving structural integrity, are } \\
\text { essential }\end{array}$ \\
$\begin{array}{c}\text { If required, the resin pattern can be checked in the } \\
\text { patient's mouth before casting it conventionally } \\
\text { adjusted (Fig. 12) }\end{array}$ \\
\hline
\end{tabular}



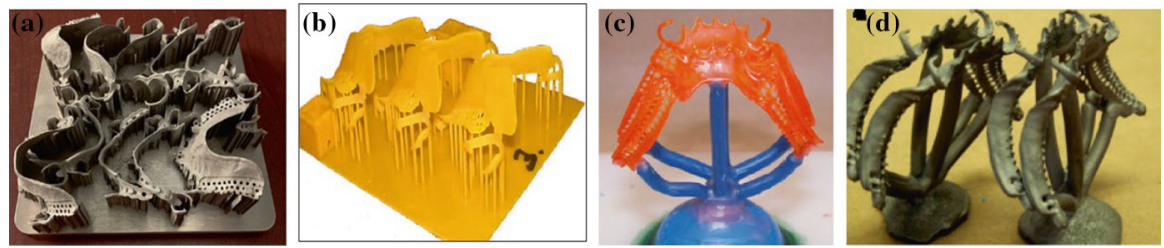

Fig. 11 Fabrication of the framework. a PRDP frameworks in the building platform processed by lasersintering technology (b) 3D-printed resin patterns of partial removable dental prostheses (c) resin pattern of PRDP framework with wax sprue ready for casting (d) metal frameworks of PRDP cast from 3D-printed resin patterns

Fig. 12 Laser-sintered partial removable dental prosthesis framework fitted on the cast

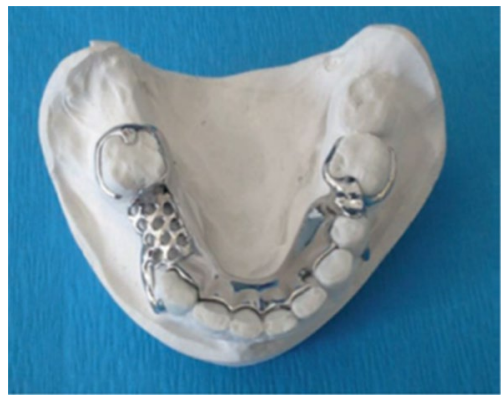

- Direct metal production systems enhance productivity, while reducing the workflow and manufacturing costs. They also minimize maintenance costs of the machines.

- Digital PRDP production is environment friendly because of decreased wastage of wax, alloy, and investment materials. The residual uncured metal powder following laser sintering can be recycled and reused.

- Virtual designs can be saved to allow clinicians to provide patients with additional or replacement prostheses having the same or a modified design. Saving virtual designs also enables their sharing between dentists and technicians through email or over the internet.

- Digital PRDP production facilitates the workflow and improves the quality of the treatment. Digitalization of the production permits the use of optimized designs with enhanced mechanical properties that are customized for each patient.

- It allows the use of multiple different materials such as polymer-based materials to overcome the limitations of metal PRDPs.

- Use of intraoral scanning is beneficial in patients with specials needs or a severe gag reflex or in anxious patients. Its sectional scanning technique allows easy moisture control, and joining together of the images allows easy identification and correction of any impression defects or deficiencies.

- Clinical trials comparing digital PRDPs to conventional have shown that digital PRDPs present fewer complications and achieve higher patient satisfaction rates than conventional PRDPs, specially when it comes to the fitting and retention of the prosthesis. 

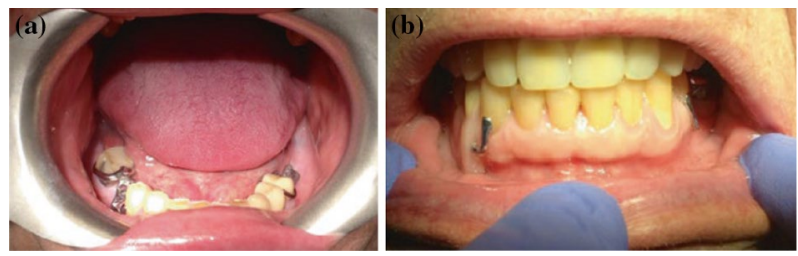

Fig. 13 Laser-sintered partial removable dental prosthesis in the mouth of a patient. a Occlusal view (b) frontal view

\section{Pitfalls and complications}

- Only the metal framework can be fabricated using the laser-sintering technology, while tooth setup is performed manually as it cannot be done digitally.

- The initial cost of the machine for digital production of PRDP is high.

- Favorable production of digital PRDP has a steep learning curve and requires time.

- During the 3D-printing process of digital PRDP, special supports are required to hold the prosthesis that needs additional steps for planning these supports and removing them following fabrication.

- The layering nature of the process of 3D-printing results in a staircase effect that can be markedly decreased by reducing the thickness of the layer. But decreasing layer thickness can increase production time.

- The technique of producing digital PRDP cannot be utilized in all patients, as it is difficult to produce some special designs due to limitations of the available software and manufacturing methods.

Acknowledgments Open Access funding provided by the Qatar National Library.

Open Access This article is licensed under a Creative Commons Attribution 4.0 International License, which permits use, sharing, adaptation, distribution and reproduction in any medium or format, as long as you give appropriate credit to the original author(s) and the source, provide a link to the Creative Commons licence, and indicate if changes were made. The images or other third party material in this article are included in the article's Creative Commons licence, unless indicated otherwise in a credit line to the material. If material is not included in the article's Creative Commons licence and your intended use is not permitted by statutory regulation or exceeds the permitted use, you will need to obtain permission directly from the copyright holder. To view a copy of this licence, visit http://creativecommons.org/licen ses/by/4.0/.

\section{Further reading}

1. F. Tamimi, H. Hirayama (eds.), Digital Restorative Dentistry, https://doi.org/10.1007/978-3-03015974-0_5 3D-Printed Removable Partial Dentures

2. Ohkubo C, Sato Y, Nishiyama Y, Suzuki Y (2017) Titanium removable denture based on a onemetal rehabilitation concept. Dent Mater J 36(5):517-523

3. Barazanchi A, Li KC, Al-Amleh B, Lyons K, Waddell JN (2017) Additive technology: update on current materials and applications in dentistry. J Prosthodont 26(2):156-163 
4. Alifui-Segbaya F, Williams RJ, George R (2017) Additive manufacturing: a novel method for fabricating cobalt-chromium removable partial denture frameworks. Eur J Prosthodont Restor Dent 25(2):73-78

5. Alageel O, Abdallah MN, Alsheghri A, Song J, Caron E, Tamimi F (2018) Removable partial denture alloys processed by laser-sintering technique. J Biomed Mater Res B Appl Biomater 106(3):1174-1185

6. Torii M, Nakata T, Takahashi K, Kawamura N, Shimpo H, Ohkubo C (2018) Fitness and retentive force of cobalt-chromium alloy clasps fabricated with repeated laser sintering and milling. J Prosthodont Res 62(3):342-346

7. Chen J, Ahmad R, Suenaga H, Li W, Sasaki K, Swain M et al (2015) Shape optimization for additive manufacturing of removable partial dentures-a new paradigm for prosthetic CAD/CAM. PLoS ONE 10(7):e0132552

8. Campbell SD, Cooper L, Craddock H, Hyde TP, Nattress B, Pavitt SH et al (2017) Removable partial dentures: the clinical need for innovation. J Prosthet Dent 118(3):273-280

9. García-Martínez I, Cáceres-Monllor D, Solaberrieta E, Ferreiroa A, Pradíes G (2020) Accuracy of digitization obtained from scannable and nonscannable elastomeric impression materials. J Prosthet Dent. https://doi.org/10.1016/j.prosdent.2020.01.002

10. Vogel AB, Kilic F, Schmidt F, Rübel S, Lapatki BG (2015) Dimensional accuracy of jaw scans performed on alginate impressions or stone models: a practice- oriented study. J Orofac Orthop 76(4):351-365

11. Almufleh B, Emami E, Alageel O, de Melo F, Seng F, Caron E et al (2018) Patient satisfaction with laser-sintered removable partial dentures: a crossover pilot clinical trial. J Prosthet Dent 119(4):560-567

12. Alghazzawi TF, Al-Samadani KH, Lemons J, Liu PR, Essig ME, Bartolucci AA et al (2015) Effect of imaging powder and CAD/CAM stone types on the marginal gap of zirconia crowns. J Am Dent Assoc 146(2):111-120

Publisher's Note Springer Nature remains neutral with regard to jurisdictional claims in published maps and institutional affiliations.

\section{Affiliations}

\section{Faleh Tamimi ${ }^{1}$ (D) Balqees Almufleh ${ }^{2,3} \cdot$ Eric Caron $^{4} \cdot$ Omar Alageel $^{2,5}$}

Balqees Almufleh

balqees.almufleh@mail.mcgill.ca

Eric Caron

eric.caron@dental-wings.com

Omar Alageel

omar.alageel@mail.mcgill.ca

1 College of Dental Medicine, Qatar University, Doha, Qatar

2 Faculty of Dentistry, McGill University, Montreal, Canada

3 Department of Prosthetic Dental Sciences, College of Dentistry, King Saud University, Riyadh, Saudi Arabia

4 Dental Wings, Montreal, Canada

5 College of Applied Dental Sciences, King Saud University, Riyadh, Saudi Arabia 